\title{
Cost Effective Treatment of Pseudo Class III Malocclusion in a Permanent Dentition with a Simple Removable Appliance
}

\section{Beena JP*}

Reader Department of Pedodontics and Preventive Dentistry, AECS Maaruti College of Dental Sciences and Research Centre, India

${ }^{*}$ Corresponding author: Beena JP, Reader Department of Pedodontics and Preventive Dentistry, AECS Maaruti College of Dental Sciences and Research Centre No 108, BTM $6^{\text {th }}$ Stage, $1^{\text {st }}$ Phase, Hulimavu Tank Bund Road Off Bannerghatta Road, Bangalore 560076 Karnataka, India, E-mail: drbeena.jp@gmail.com

Citation: Beena JP (2015) Cost Effective Treatment of Pseudo Class III Malocclusion in a Permanent Dentition with a Simple Removable Appliance. J Case Rep Stud 3(3): 305. doi: 10.15744/2348-9820.3.305

Received Date: February 02, 2015 Accepted Date: June 09, 2015 Published Date: June 11, 2015

\section{Abstract}

Treating a Class III malocclusion has always been a challenge to the clinician beginning with the proper diagnosis, treatment options and the time of treatment. Few are of the opinion that the malocclusion should be corrected as soon as it is noticed while others prefer to wait it out till late mixed dentition or permanent dentition. However there only a few willing to take the middle path and hence correcting this malocclusion during early mixed dentition period utilizing the optimal growth potential of the growing orofacial musculature. This article describes a Hawleys appliance with anterior expansion screw to correct anterior cross bite in pseudo Class III malocclusion with permanent dentition in a patient who could not afford fixed orthodontic therapy.

Keywords: Pseudo Class III; Hawleys appliance; Expansion appliance

\section{Introduction}

The time to start orthodontic treatment for Class III malocclusion has created considerable ambiguity among the dental profession. With some of the opinion that appliances should be placed in the primary dentition to early mixed dentition while others are have the opposite view and prefer to wait till the later part of mixed dentition.

One of the main reasons for ambiguity in treatment plan for treating Class III lies in the misinterpretation of classifications of this malocclusion. When dealing with Class III malocclusion confusion may arise as three types of malocclusion can have the same appearance [1,2], True skeletal Class III malocclusion, the simple anterior crossbite and pseudo Class III malocclusion. Each has a distinct etiology which serves to differentiate them. In a true Class III malocclusion as described by Angle [3], the lower molar is mesially positioned relative to the upper first molar. This relationship may result from skeletal discrepancy which is characterized by mandibular protrusion and a normal maxilla, or maxillary retrusion and a normal mandible, or a combination of maxillary retrusion and mandibular protrusion [2,4]. The dental components are usually characterized with proclined maxillary incisors and retroclined mandibular incisors to achieve dentoalveolar compensation $[2,4]$. In the second type of Class III malocclusion, a simple anterior crossbite is usually the result of linguoversion of one or more maxillary incisors without forward mandibular movement, or true skeletal component [1].

In pseudo Class III malocclusion, Moyers [5] suggested that it is a positional mal-relationship with an acquired neuromuscular reflex pattern of mandibular closure. Pseudo Class III malocclusion is usually characterized by Class I or mild Class III skeletal relationship, retroclined maxillary incisors with upright positioned lower incisors on the basal bone, incisors in edge to edge relationship in Centric relation (CR) and anterior cross bite in Centric occlusion(CO) [1,2]. Graber et al [6] attributed the incisor interference to retroclined upper incisors and proclined lower incisors. During habitual closure to achieve maximum intercuspation, the lingually inclined maxillary incisors glide down the lingual surfaces of the mandibular incisors [1], so as to disengage the incisors and bring the posterior teeth into full occlusion. This results in a forward displacement of mandible and an anterior crossbite. The principles applied to each case to determine the time of treatment is dictated by the detrimental effects of the malocclusion, on the development of the environmental forces of occlusion, on the path of eruption of the remaining unerupted permanent teeth and on the growth of the alveolar bone [7].

Keeping these factors in mind during treatment planning, helps achieve a harmonious relationship between the teeth, jaw and environmental factors which lead to a good functional relationship at an early age. 


\section{Case report}

A 12 year old male patient reported with chief complaint of lower anterior teeth overlapping upper teeth. He came to Pediatric dentist as a last resort because he could not afford the cost of fixed orthodontic treatment suggested to him. He was extremely conscious about his teeth and the way he looked. He was from a low socioeconomic background and no one else had this problem in his family.

Extra oral examination revealed slight concave profile with retruded upper lip and prominent lower lip Figure 1 \& 2.

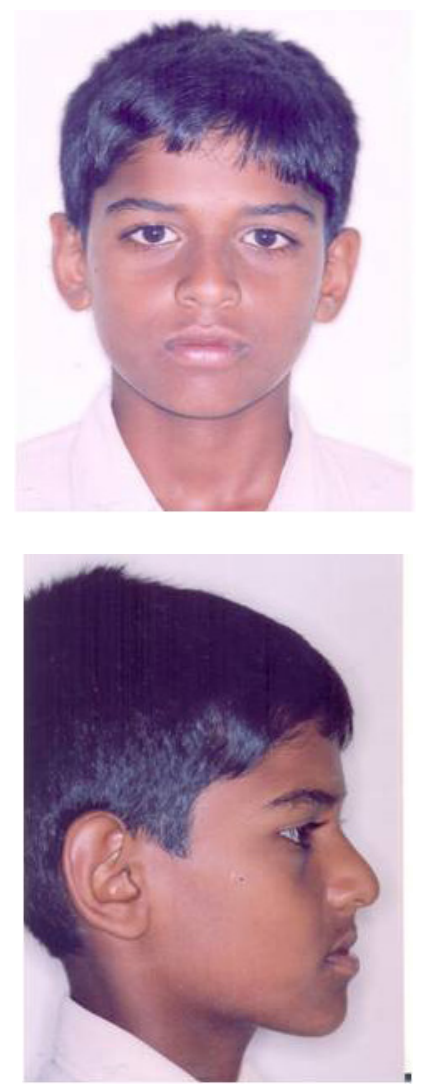

Intra oral examination revealed a permanent dentition except for third molars. 12, 11 and 21 were in crossbite Figure 3. The molar relation on right side was Angle's Class III and left side was Class I. Patient had a forward path of closure of the mandible. On assessment of $\mathrm{CO}$ and $\mathrm{CR}$ discrepancy and guidance of the mandible on closure, edge to edge relationship was seen with respect to 21 and 11, 12 were still in crossbite. Model analysis revealed a tooth size discrepancy of $2.5 \mathrm{~mm}$ in the maxillary arch. Panoramic radiograph demonstrated normal tooth and bone development with no pathological findings.

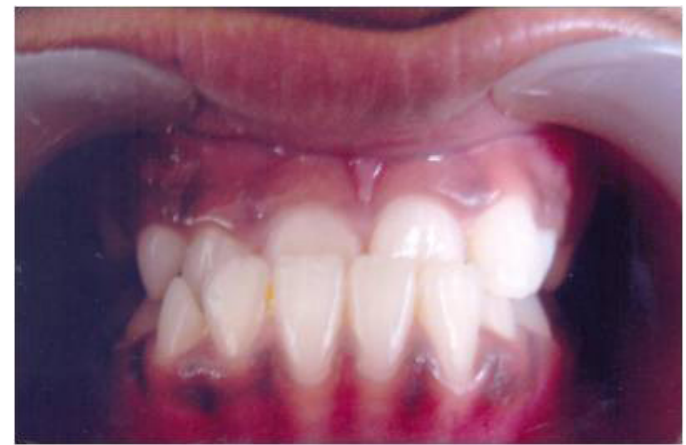

\begin{tabular}{|c|c|c|}
\hline SNB angle & $80^{\circ}$ & $84^{\circ}$ \\
\hline ANB & $2^{0}$ & $-2^{0}$ \\
\hline Upper inscisor to NA angle & $22^{\circ}$ & $20^{\circ}$ \\
\hline Upper incisor to NA (linear) & $4 \mathrm{~mm}$ & $-2 \mathrm{~mm}$ \\
\hline Frankfort mandibular incisor angle & $60^{\circ}-75^{\circ}$ & $73^{\circ}$ \\
\hline
\end{tabular}

Diagnosis was of Pseudo Class III malocclusion with anterior cross bite with respect to 12,11 and 21

Table 1: Cephalometric analysis 


\section{Treatment}

Bite was registered by guiding the mandible distally in incisor edge to edge relation for mounting the upper and lower cast for appliance fabrication. Finished appliance consisted of labial bow, adams clasp, triangular clasps for retention and Jack screw incorporated for dento-alveolar expansion with respect to 12,11 and 21 with posterior bite plane to disocclude the posterior teeth and open the bite Figure $4 \& 5$. The expansion screw was activated half turn every alternate day. The patient was advised to use the appliance continuously except during eating. The patient was reviewed every week as a part of our rural dental health camp. The anterior cross bite was corrected in 3 months time with the establishment of over jet of $2 \mathrm{~mm}$ Figure 6 . There was improvement in the patients profile from concave to straight. The molar relationship established was Class III on the right and Class I on the left.
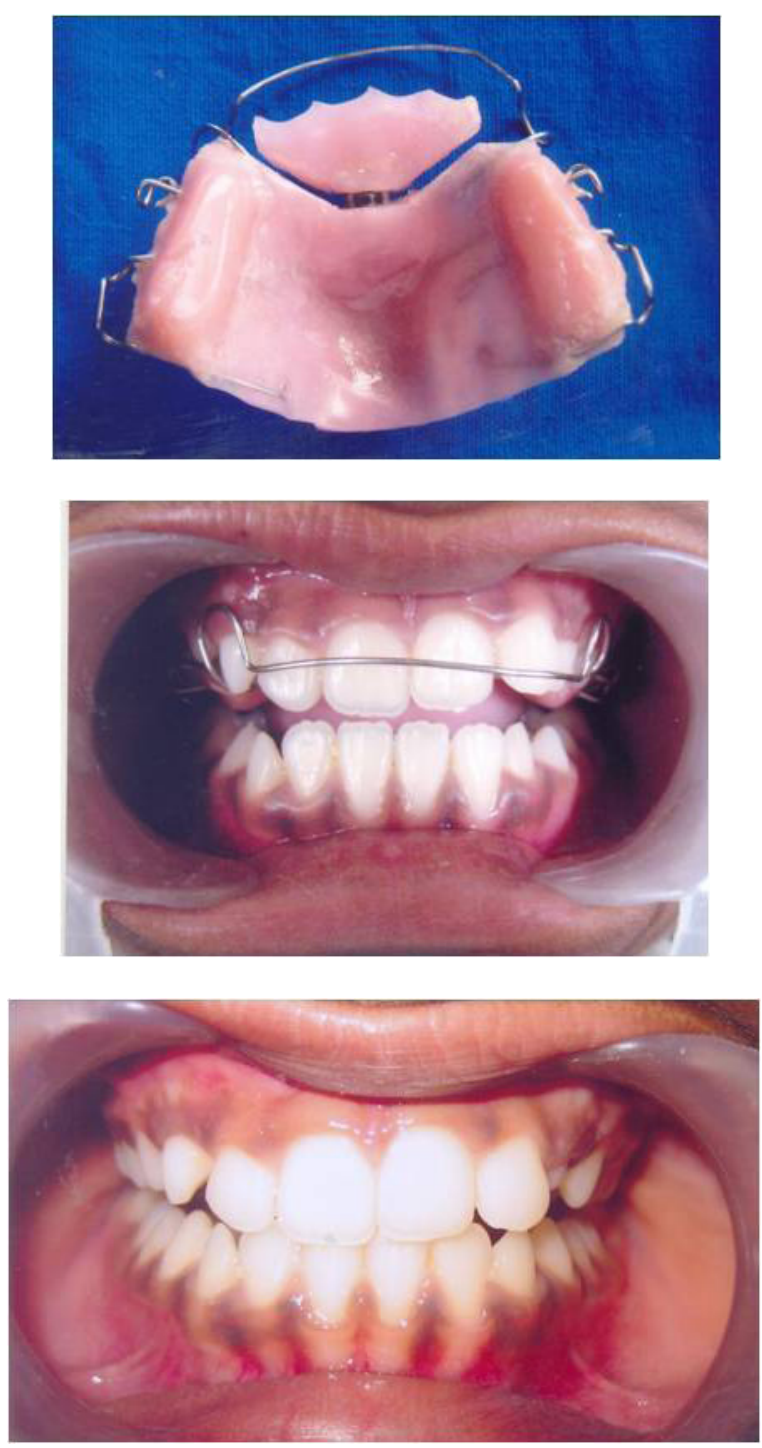

Post treatment cephalometric radiograph could not be obtained because of the patient compliance, as he was from a rural area and could not come to the hospital. Only photographic record could be obtained as we visited the place as a part of rural dental health camps.

\section{Discussion}

The incidence of Class III malocclusion is rather small in the population but it is one of the most difficult malocclusions to treat. Class III malocclusions in children may have an underlying skeletal and dental component [4]. Class I molar relationship can exist in both centric relation and centric occlusion, or there may be shift from Class I to a Class III molar relationship on mandibular closure [5]. On cephalometric analysis, pseudo Class III malocclusion shows a normal SNA if diagnosed early, whereas SNB could be slightly increased because of forward positioning of the mandible. In contrast, in true class III cases, a large SNB angle or a small SNA angle may be found, depending on whether the result is due to an underdeveloped maxilla or a long mandibular base, or both. In addition, the mandibular incisors may depict a retroclination, thus lessening the IMPA [2]. The final diagnosis of the type of Class III malocclusion relies heavily on (i) clinically establishing the dual closure pattern by asking and guiding the patient to bite 
in normal centric and habitual positions, (ii) observing any familial tendency, (iii) cephalometric parameters, and (iv) incisor relationships. Both these types of malocclusion, if untreated early, may affect the normal growth and development of the skeletal bases, leading to restricted maxillary growth and maybe mandibular overgrowth. Most of the cases are however a combination of the above factors, where there is (a) skeletal discrepancy which has been aggravated by a positional molar relation of the mandible or vice versa and (b) a prolonged positional malrelation causing a skeletal change. Both these conditions require intervention [8].

Many authors have recommended early treatment of Class III malocclusion which exhibited dental and skeletal components tends to become worse with age. They believe that early intervention is an advantage in the early mixed dentition as well as in the deciduous dentition. Advantages include correcting anterior crossbite to allow normal dental base development and subsequent favorable skeletal growth, preventing habits such as bruxism, eliminating traumatic occlusion and reducing the length of treatment time with fixed appliance [9]. The optimum period for treatment suggested is between the ages of 6-9 years [6,10,11]. Several clinicians however still avoid early correction of the pseudo Class III in the deciduous dentition because of poor stability and unfavorable experiences with behavior of young patients [12]. Some practitioners prefer to wait for permanent maxillary incisors to erupt before starting treatment due to natural tendency of the teeth to erupt in a lingual position during dental arch development [13].

The various therapies suggested for the correction of an anterior crossbite and which may correct skeletal problems in young patients include face mask therapy [14], chincaps [10], and functional appliances [15]. The functional appliances used to treat Class III malocclusion work by permitting the eruption of the maxillary molars and maintaining the mandibular ones in position, leading to an occlusal plane rotation that helps shift the molar relationship from Class III to Class I [16]. Face mask protraction creates a counterclockwise rotation of the maxilla and a clockwise rotation of the mandible while increasing the inferior facial height and turning the patient's profile more convex [17].

Other alternative treatments include fixed [18] and/or removable appliances [19] which are effective methods of treating a Class III incisor mal relation. A common technique is to use a simple edgewise appliance (molar tubes and incisor brackets) to advance the incisors into a normal overjet. Although the force can be produced by compressing a rectangular superelastic wire between the molar tube and incisor brackets, deflecting the additional arch length away from the line of action, this method offers limited control and may cause cheek impingement [20]. Alternatively, an open-coil spring on a more rigid wire can be compressed against the molar tube to push the incisors labially. A problem with this technique, however, is that 4-5mm of wire will extend beyond the molar edgewise or headgear tube (the bimetric arch) [21,22], which may cause soft tissue discomfort.

Although the patient reported to the pediatric dentist during the late mixed dentition period we could still effectively correct the malocclusion with a removable appliance. Thus emphasizing the fact that little dento-alveolar changes that can be brought about by a removable orthodontic appliance can go a long way in bringing about drastic changes in a patient's profile.

Hawley's appliance with an anterior expansion screw used in this case was the most simple and cost effective treatment we could give our patient considering the fact that he could neither afford fixed orthodontic treatment suggested to him nor could he visit the hospital due to the distance. When compared to cost of fixed orthodontic therapy the cost of fabricating this removable appliance with acrylic and orthodontic wires was very minimal. Hawley's appliance with an anterior expansion screw used in this case was the most simple and cost effective treatment we could give our patient considering the fact that he could neither afford fixed orthodontic treatment suggested to him nor could he visit the hospital due to the distance. Though we could not achieve skeletal changes with respect to molar relation, the simple dentoalveolar changes brought a dramatic change in the patient's life, attitude and made him more confident, which made all our efforts worthwhile.

\section{Conclusion}

Treatment of Psuedo Class III malocclusion should be treated as early as possible when detected. Treatment during mixed dentition phase gives a stable result by influencing the alveolar growth to its full potential with the aid from environmental forces. The aim of mixed dentition treatment should be minimal but effective use of appliances to provide desired correction of malocclusion, thereby minimizing or preventing the use of or reducing the duration of fixed mechanotherapy.

\section{References}

1. Mamandras AH, Magli LA (1984) Orthodontic treatment of pseudo Class III malocclusion. A case report. J Can Dent Assoc 50: 779-81.

2. Rabie AB, Gu Y (2000) Diagnostic criteria for pseudo Class III malocclusion. Am J Orthod Dentofacial Orthop 117: 1-9.

3. Angle EH (1900) Treatment of malocclusion of the teeth and fractures of the maxillae: Angle's System (6 ${ }^{\text {th }}$ edn) Philadelphia: SS White Dental Manufacturing, USA.

4. Guyer EC, Ellis EE, McNamara JA, Behrents RG (1986) Components of Class III Malocclusion in Juveniles and Adolescents. Angle Orthod 56: 7-30.

5. Moyers RE (1988) Handbook of orthodontics ( $4^{\text {th }}$ edn) Year Book Medical Publishers, USA.

6. Graber TM, Rakosi TH, Ptrovic AG (1997) Dentofacial orthodontics with functional appliance (2 ${ }^{\text {nd }}$ edn) St Lois: Mosby publisher, USA.

7. SJ Kloehn (1979) Fourteenth General Meeting of the Edward H. Angle Society of Orthodontia 1949 3: 75-96.

8. Kapur A, Chawla HS, Utreja A, Goyal A (2008) Early Class III occlusal tendency in children and its selective management. J Indian Soc Pedod Prev Dent 26: 107-13. 
9. Giancotti A, Maselli A, Mampieri G, Spano E (2003) Psuedo Class III malocclusion treatment with Balters Bionator. J Orthod 30: $203-15$.

10. Allen RA, Connolly IH, Richardson A (1993) Early treatment of Class III incisor relationship using the chincap appliance. Eur J Orthod 15: $371-6$.

11. Nanda R (1978) Protraction of maxilla in rhesus monkeys by controlled extraoral forces. Am J Orthod Dentofac Orthop 74: 121-41.

12. Turley PK (1996) Orthopedic correction of Class III malocclusion: Retention and phase II therapy. J Clin Orthod 30: $313-24$.

13. Rabie AB, Gu Y (1999) Management of Pseudo Class III malocclusion in Southern Chinese Children. Br Dent J 186: 183-7.

14. dos Santos-Pinto A, Paulin RF, Melo AC (2001) Pseudo-Class III treatment with reverse traction: case report. J Clin Pediatr Dent 25: 267-74.

15. Eganhouse GR (1997) Two-piece corrector for Class III skeletal and dental malocclusion. J Clin Orthod 31: 246-51.

16. Bilodeau JE (2011) Nonsurgical treatment of a Class III patient with a lateral open-bite malocclusion. Am J Orthod Dentofacial Orthop 140: 861-8.

17. Turley PK (2007) Treatment of the Class III Malocclusion with Maxillary Expansion and Protraction. Seminars in Orthodontics 13: 143-57.

18. Lee BD (1978) Correction of crossbite. Dent Clin North Am 22: 647-68.

19. Ngan P, Hagg U, Yiu C, Merwin D, Wei SH (1966) Treatment response to maxillary expansion and protraction. Eur J Orthod 18: $151-68$.

20. Bowman SJ (2008) A quick fix for pseudo-Class III correction. J Clin Orthod 42: 691-727.

21. Wilson WL, Wilson RC (1981) Modular Orthodontics, Rocky Mountain Orthodontics, Denver, 1981.

22. Harnick DJ (1998) Case report: Class II correction using a modified Wilson bimetric distalizing arch and maxillary second molar extraction. Angle Orthod 68: 275-80.

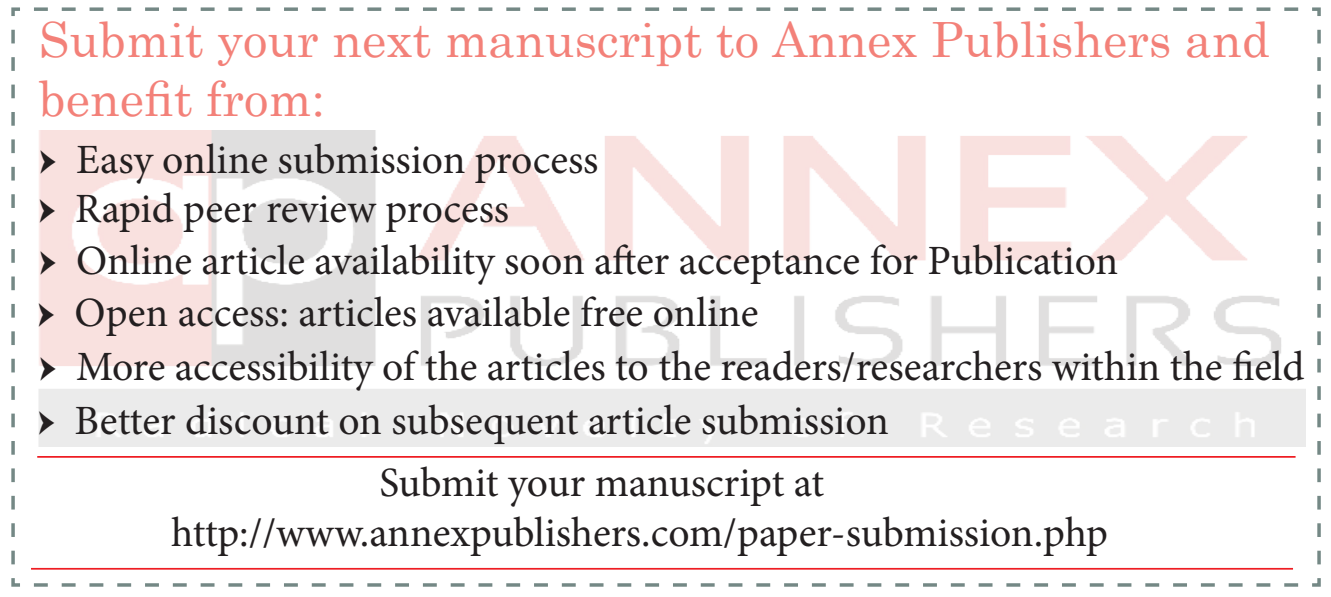

